\title{
Entre el exilio y la revolución: Komin-Alexandrovsky, Anatol Gorelik y Mijail Yaroshevsky
}

\author{
Between the exile and the revolution: Komin-Alexandrovsky, \\ Anatol Gorelik and Mikhail Yaroshevsky
}

\author{
Roberto Pittaluga \\ Universidad Nacional de la Pampa \\ IdIHCS-FaHCE-UNLP/UBA, Argentina
}

Recibido: 31/07/2017

Aceptado: 15/10/2017

Resumen: El presente artículo expone y analiza las elaboraciones sobre la revolución en Rusia realizadas por tres militantes exiliados en Buenos Aires: Mijail Yaroshevsky, Komin-Alexandrovsky y Anatol Gorelik. Su situación de exilio es contrastante: los dos primeros llegaron a Buenos Aires escapando del régimen zarista, y regresarán a Rusia años después de 1917; Gorelik, en cambio, protagonista de la revolución en Ucrania en las filas del anarquismo, fue detenido, mantenido en prisión y después expulsado por el gobierno bolchevique; tras un breve paso por Berlín recaló finalmente en Buenos Aires en 1922. Los tres dejaron una serie de escritos sobre la revolución de enorme importancia a la hora de interpretar las recepciones del fenómeno soviético más allá del ex imperio, como también sus reales alcances, es decir, las dimensiones de una revolución que sería, al menos en sus primeros años, difícil de comprender desde una mirada que la encapsule en sus demarcaciones "nacional-estatales".

Palabras claves: Revolución soviética, exilio, comunismo, anarquismo

Abstract: The present article exposes and analyzes the elaborations about the revolution in Russia carried out by three militants exiled in Buenos Aires: Mijail Yaroshevsky, Komin-Alexandrovsky y Anatol Gorelik. Their situation of exile is contrasting: the first two arrived in Buenos Aires escaping the tsarist regime, and 
they will return to Russia years after 1917. Gorelik, instead, protagonist of the revolution in Ukraine in the anarchism movement, was arrested, held in prison and then expelled by the Bolshevik government; after a brief passage through Berlin, he finally ended up in Buenos Aires in 1922. The three left a series of writings on the revolution of enormous importance at the moment of interpreting the receptions of the Soviet revolution beyond the ex empire, as well as its real scope, that is, the dimensions of a revolution that would be, at least in its early years, difficult to understand from a perspective that encapsulates it in its "national-state" demarcations.

Keywords: Soviet revolution, exile, communism, anarchism

\section{Yaroshevsky: causalidad y sobredeterminación de la revolución ${ }^{1}$}

Apenas unos días después de las insurrecciones "de febrero" de 1917 en Rusia, un exiliado ruso en la Argentina, Mijail Efimovich Yaroshevsky, las caracterizaba ya, en las páginas de Nosotros del 24 de marzo de ese año, como una revolución de corte socialista:

"Sobre el Palacio de Invierno, construido por Nicolás I, donde el Poder histórico efectuaba sus actos más solemnes, cuyas salas lujosas tantas veces fueron testigos de conspiraciones contra las reivindicaciones populares, enfrente del cual el $22 \mathrm{de}$ enero de 1905 fue diezmada la muchedumbre que llegó con la muy humilde petición al zar, flamea ahora la bandera roja." ${ }^{2}$

Si tenemos en cuenta las diferencias entre los calendarios juliano y gregoriano, resulta a primera vista sorprendente que desde un exilio "tan lejano" se pueda tener, sobre el filo de los acontecimientos, una anticipación tan certera. Yaroshevsky expresa su ambición apasionada por "prever el porvenir cercano", por conocerlo "no como él se nos aparece en nuestros deseos y esperanzas, sino cual en realidad será”, o al menos afrontar la tarea de "encadenar los sucesos acaecidos, a fin de prever los que acaecerán". 3 Y si bien el texto no puede dar cuenta de ese carácter "socialista" de la revolución, de todos modos construye un pronóstico a base de indicios.

\footnotetext{
${ }^{1}$ Un fragmento de este texto se publica en el $\mathrm{n}^{0} 21$ de Prismas. Revista de Historia Intelectual de la Universidad Nacional de Quilmes este mismo año.

2 YAROSHEVSKY, Mijail, "La revolución en Rusia”, en Nosotros, año XI, nº 95, Buenos Aires, marzo de 1917, p. 289.

3 Ibíd., 290.
} 
El informado y claro análisis que ofrece de la dinámica de enfrentamientos entre las formas hasta entonces dominantes de la representación política se recorta sobre un fondo conflictual de mayor profundidad, entre un Estado feudo, de carácter patrimonialista y en decadencia ("conservábase en la corte del zar esta idea del estado bien de familia"4) cuyas clases dominantes no atinaban sino a reforzar su hundimiento, y una "nación rusa" que, si todavía en ciernes, se había ido conformando paulatinamente merced a la mayor integración del país en el mercado y la producción capitalistas; nación que demandaba, históricamente, otro tipo de andamiaje estatal y otras formas de representación política. $5 \mathrm{Si}$ destaca que desde antes de la revolución crecía "la influencia de la Duma", a la par que se creaban "organizaciones colosales, cooperativas, la unión de las municipalidades y de los consejos provinciales o zemtswos"6, el saldo concreto de "la arrojada iniciativa del pueblo" es, precisamente, que "ha derrumbado uno de los fundamentos míticos del edificio nacional, ha acabado con una de las tres ballenas que soportaban la tierra rusa: el poder de los zares".7 Sin embargo, esa presentación de lo acaecido no alcanza su verdadera significación sino en un pronóstico que se advierte en su lectura indicial de los acontecimientos, como cuando apunta que "el liberalismo ruso, que parecía orgánicamente incapaz para la táctica revolucionaria" debió recurrir "a un golpe de estado" para desplazar al zar, "y el presidente de la Duma, Rodzianko, moderadísimo octubrista y conocido conservador en su actuación en el zemtsvo de su provincia, se convierte en presidente del comité jacobino de seguridad!”. ${ }^{8}$

La Duma encontraba en el movimiento popular, continúa nuestro autor, el apoyo que necesitaba para salir airosa de su confrontación con la corona, mientras que el pueblo (no sólo "los civiles" sino también "el ejército [...] que fraternizó con los amotinados"), que inicialmente se moviliza acuciado "por el aprovisionamiento", hallaba respaldo en esa representación nacional. 9 Yaroshevsky en ningún momento funde ambos componentes de la revolución, como tampoco les asignará, en siguientes artículos, el mismo protagonismo; mantiene esta diferencia como clave de lectura de

\footnotetext{
4 Ibíd., 293.

5 Ibíd.,

${ }^{6}$ Ibíd., 291.

7 Ibíd., 294; destacado en el original.

8 Ibíd., 290. A lo que agrega, afectando sorpresa: "Lo escribo y me cuesta creerlo, tanto esta realidad se asemeja a un cuento", ibíd.

9 Ibíd., 292.
} 
la propia revolución, y colige su dinámica de la tensión entre ambos modos de acción y expresión política. Asimismo, evita simplificar las causas de la movilización popular a "las deficiencias del aprovisionamiento" o al hartazgo de la guerra, pues "las masas sublevadas evidentemente llevaban en su seno una suficiente cantidad de elementos organizadores y conscientes, como para dar al movimiento un carácter político". ${ }^{10} \mathrm{En}$ el cuadro que pinta a través de diversos artículos, sobresalen los énfasis en la autonomía de las emergentes organizaciones de las masas sublevadas respecto de cualquier poder preconstituido.

Yaroshevsky había llegado a la Argentina escapado de las prisiones zaristas en algún momento posterior a 1914, según la reconstrucción biográfica emprendida por Lazar Jeifets y Víctor Jeifets a partir de los datos que se preservan de este activista y militante comunista en los archivos de la ex URSS. Nacido en Soroki, Besarabia, en 1880, en el seno de una familia judía cuyo padre era empleado, estudió, en primer término, en el Instituto de Lenguas Modernas de Vilna y posteriormente en el Instituto de Comercio de Petrogrado. Enlistado en el ejército zarista, de joven se sumó a las filas del Bund. ${ }^{11}$ Ya en la Argentina, sus actividades están aún menos documentadas, aunque se sabe que su activismo en los grupos de exiliados rusos que adherían al Partido Socialista Argentino (PSA) se combinaba con publicaciones en los campos de su formación. Desde el estallido revolucionario publica una serie de textos sobre la revolución en Rusia en medios locales muy diversos, desde La Razón a La Protesta, de La Vanguardia a La Internacional, de Documentos del Progreso a Nosotros. ${ }^{12}$ Entre 1918 y 1920 traduce distintos textos de Lenin para su publicación en Argentina -de los cuales destaca El estado y la revolución proletaria-y en 1921 y 1922 se desempeña como Jefe de la Sección Sudamericana de la Comintern y en otros cargos vinculados a las relaciones de la Internacional Comunista (IC) y América Latina. ${ }^{13}$

En textos posteriores a ese temprano escrito de marzo de 1917, Yaroshevsky irá

\footnotetext{
10 Ibíd.,

11 JEIFETS, Lazar; JEIFETS, Víctor, América Latina en la Internacional Comunista, 1919-1943. Diccionario Biográfico, Santiago de Chile: Ariadna Ediciones, 2015, p. 660.

12 PITTALUGA, Roberto, Soviets en Buenos Aires. La izquierda de la Argentina ante la revolución en Rusia, Buenos Aires: Prometeo Libros, 2015.

13 JEIFETS, Lazar; JEIFETS, Víctor, América Latina...., ob. cit., p. 660.
} 
precisando ese "pronóstico" construido sobre algunos indicios. ${ }^{14} \mathrm{El}$ sesgo que tomaba aquella gesta no parecía radicar tanto, a su juicio, en las medidas gubernamentales, sino en el nuevo y particular escenario político que se instaura. Hay un sagaz tratamiento en torno a las causas de la revolución, examen que procede por cortes y desplazamientos sutiles - pero no para ir descartando, sino para ir complejizando. Por un lado, en su argumentación, la revolución surge tanto de las condiciones históricas rusas de largo aliento -desde un perspectivismo no exento de tintes teleológicos15- como de la particular coyuntura que impone la guerra, y "tuvo principio en las filas del pan, delante de las panaderías. La empezaron mujeres del pueblo. El primer comisario de policía caído fue matado por un cosaco. Se trata, pues, de elementos desligados de cualquier organización revolucionaria o política en general". ${ }^{16}$ Sin embargo, la situación resulta insuficiente para explicarla; las condiciones existentes dan cuenta de ciertos aspectos, pero la revolución excede su contexto de emergencia.

Poco tiempo después, en junio de 1917, en las páginas de La Vanguardia, Yaroshevsky avanzaba en esa línea interpretativa y sostenía que "la revolución rusa", esa "nueva aurora en la vida de la humanidad" que iniciaba la creación de "formas nuevas y solidarias de vida social", era el "triunfo de la democracia", que en la tradición rusa implicaba "no sólo una reforma política" sino "también el triunfo de la justicia social" ${ }^{17} \mathrm{Y}$ cuando decía "democracia" estaba refiriéndose - como aclara un par de años después- a que "el verdadero carácter de esta revolución, como revolución obrera-campesina" residía en "la nueva fuerza popular surgida de ella en

14 Por razones de espacio, el tratamiento de las problemáticas que siguen se expone de modo extremadamente condensado; una presentación más amplia de estas cuestiones y sus implicancias para las distintas particiones de la izquierda, en PITTALUGA, Roberto, Soviets en Buenos Aires..., ob. cit.

15 "La revolución no fue preparada ni organizada por nadie en el sentido como se preparan las revueltas de cuartel o de corte. La preparó, sí, y realizó un ser impersonal que se llama necesidad histórica", YAROSHEVSKY, Mijail, "Estudio sobre la revolución rusa", en Documentos del progreso, $\mathrm{n}^{\mathrm{0}}$ 6, Buenos Aires, 15 de octubre de 1919, p. 10.

16 Ibíd.

17 YAROSHEVSKY, Mijail, "El espíritu de la revolución rusa”, en La Vanguardia, Buenos Aires, 10 de junio de 1917, p. 2. O. Figes y B. Kolonitskii mostraron que luego de febrero de 1917 "la palabra democracia era sinónima de organizaciones democráticas (por ejemplo, los soviets, los comités de fábrica, etc.)", punto de vista bajo el cual "la tarea de la democracia era la misma que la de la revolución social". Las resoluciones de los trabajadores y de los soldados "interpretaban claramente el poder de los Soviets como el establecimiento de un gobierno auténticamente democrático”, lo que por entonces, en los círculos soviéticos, se denominaba "la dictadura de la democracia", pues ningún partido burgués podía ser democrático; cfr. FIGES, Orlando y KOLONITSKII, Boris, Interpretar la Revolución Rusa. El lenguaje y los símbolos de 1917, Valencia, Biblioteca Nueva/Universitat de València, 2001, pp. 162-163, énfasis en el original. 
forma de Consejos de Obreros, Campesinos y Soldados". ${ }^{18}$. Es el protagonismo conjunto de "las multitudes obreras y campesinas y las vanguardias organizadas de aquéllas en la construcción política"19 que son los soviets, lo que marca el tono de la revolución, y es realmente, para este exiliado, su causa profunda como novum, como aquello que hace de una insurrección por el hambre, el hastío de la guerra y contra el autoritarismo, un acontecimiento revolucionario. Corte, desplazamiento y complejización de las causalidades: aparición en el contexto de una novedad. Una subjetivación revolucionaria que nuestro autor capta como "la nueva personalidad histórica nacida con la revolución", la cual se manifiesta "en estos mítines y en las organizaciones surgidas de ellos". ${ }^{20}$ Mujeres, trabajadores, soldados, campesinos, dejan de ser meramente tales para convertirse en activos de las nuevas organizaciones que ponen en pie a la revolución, y "el proletariado socialista organizado es el spiritus rector de esta formidable organización". ${ }^{21} \mathrm{El}$ reconocimiento de la potencia de las subjetivaciones y las formas organizativas que surgen y dinamizan la revolución es lo que lleva a Yaroshevsky a pensar en los acontecimientos de febrero como portadores de las transformaciones sociales que se vislumbrarán más claramente hacia fines de ese 1917, cuando para el II Congreso Panruso, los soviets reconozcan su verdadera capacidad y poder. ${ }^{22}$

Sin embargo, estas apreciaciones sobre el carácter y la dinámica de la revolución no llevan a Yaroshevsky a fijarla a algún curso inexorable, o a resolver sus múltiples rostros en alguna causa-madre. Precisamente porque se trata de un proceso de subjetivación, una analítica crítica de la revolución requiere de una descomposición de lo que parece evidente. ${ }^{23}$ Cuando se cumple el primer aniversario de la revolución, publica un artículo en el cual el proceso revolucionario es exhibido

\footnotetext{
${ }^{18}$ YAROSHEVSKY, Mijail, “Estudio ...”, ob. cit., p. 12; el énfasis me pertenece.

19 Ibíd.

20 Ibíd.

${ }^{21}$ Ibíd.

22 Una percepción similar se expresa en la persistente traducción de bolchevique por maximalista que predomina en la prensa izquierdista rioplatense; ver al respecto, el apartado "La confusión maximalista" en PITTALUGA, Roberto, Soviets en Buenos Aires ..., ob. cit., pp.189-95. Yaroshevsky entrecomilla el término "maximalismo" como traducción de bolchevique para referirse a la idea "de hacer juntas la revolución contra el zarismo y la revolución social contra la burguesía" tal como, agrega, Trotsky "defendía y propagaba en el año 1905"; cfr. YAROSHEVSKY, Mijail, "La tragedia rusa. Figuras del gobierno maximalista”, en La Protesta, Buenos Aires, 24 de noviembre de 1917, p. 2.

$23 \mathrm{Al}$ igual que el trabajo de discusión sobre ciertos términos - como soviet, revolución, bolchevique, socialismo, democracia- que se produce en la izquierda de la época; cfr. PITTALUGA, Roberto, Soviets en Buenos Aires..., ob. cit.
} 
por medio de un montaje de "escenas" en un registro anecdótico y literario, de modo que el texto procede primero a descomponer dicho proceso para revelar sus complejidades y contradicciones, y a recomponerlo luego en un cuadro -pues se trata, efectivamente, de una escritura que tiene el propósito de mostrar- que ya no puede ser visto de modo homogéneo. Por el contrario, las que se exponen son las brechas y las distancias entre aspectos de la revolución, o las interrupciones y los saltos en su movimiento.

En Escenas de la revolución rusa en provincia (con motivo del primer aniversario), ${ }^{24}$ Yaroshevsky puede así presentar al viejo poder disolviéndose en el aire: el obstinado ocultamiento de los cables que llegaban desde Petrogrado o Moscú por parte de autoridades locales fieles al ancien régime ya no tiene efectos por el desplazamiento del teatro de la política a unas "esquinas [en las que] los vecinos comunicábanse unos a otros su contenido con exactitud estenográfica", ${ }^{25}$ del mismo modo, quienes "se preparaban para una lucha mortal" contra el régimen y saludaban eufóricos la solidaria huelga ferroviaria, se percataron de repente con que "no hubo con quien pelear" pues "el terrible enemigo que parecía un monstruo invencible quedó reducido a polvo en un soplo". ${ }^{26}$ La imagen de la revolución como batalla, como asalto del poder es puesta en entredicho en el texto de nuestro autor, mediante este trabajo de descomposición y recomposición convergente con una mirada aguzada, que hurga en el detalle y la anécdota con fines críticos.

Por este procedimiento, Yaroshevsky puede apreciar las fuerzas de la revolución tanto en "el júbilo tranquilo" con que "los acontecimientos fueron acogidos" en los suburbios y las fábricas "como si todo lo supiesen y esperasen", como en los desfiles de los "destacamentos militares, en filas bien ordenadas, con banderas rojas, las bayonetas adornadas también con cintas coloradas" que pasan por el mercado, mientras "los soldados cantan cantos revolucionarios" como La Marsellesa “y el sol primaveral brilla sobre las bayonetas". ${ }^{27} \mathrm{Y}$ esta misma dualidad en el seno de las fuerzas revolucionarias puede conjugarse, muestra el autor, con el desciframiento

\footnotetext{
24 YAROSHEVSKY, Mijail, "Escenas de la revolución rusa en provincia (con motivo del primer aniversario)", en Nosotros, año 12, $\mathrm{n}^{0}$ 108, Buenos Aires, abril 1918, pp. 463-472. Nótese que el aniversario es el de la llamada "revolución de febrero"; un análisis más extenso de este texto en PITTALUGA, Roberto, Soviets en Buenos Aires... , ob. cit., pp. 360-63.

25 Ibíd., p. 463.

${ }^{26}$ Ibíd., pp. 467-68.

27 Ibíd., p. 466.
} 
de la caída del zar en la clave del conflicto entre germanófilos y eslavófilos, mientras las proclamas socialistas no siempre eran bien comprendidas por la gente sencilla. ${ }^{28}$ Las contradicciones se multiplican en las filas de la revolución, que deja de ser entonces un acontecimiento transparente para presentarse como un complejo sobredeterminado. Contradicciones que quedan en suspense, sin resolverse en el texto, como la actitud de ese general, hasta ayer "misionero por vocación y reaccionario militante de la «banda negra» [que] manifestó espíritu de iniciativa” y "adornado el pecho con una enorme cinta roja, recorría las oficinas bajo su jurisdicción, pregonando la libertad y la república venidera”.29 La igualdad a la que daría lugar el fin del régimen - “ Ahora uno, aun siendo zar, no tiene seguro su pan de todos los días. Tendrá que aprender el sarievitch algún otro oficio" dice burlonamente un obrero- convive con el lamento de una trabajadora ya anciana porque al heredero al trono "no lo dejaron al pobrecito reinar siquiera un ratito"..$^{\circ}$

Nuestro autor no sutura esas contradicciones y tensiones, no las resuelve en una novela moralizante; las deja planteadas como elementos causales de la propia dinámica revolucionaria, cuyo acento, de todos modos, está puesto en esos diálogos, en esas escenas novedosas de deliberación y acción que se articulan bajo el principio del soviet. ${ }^{31}$ Estas "escenas" sobredeterminadas que bosqueja, brindan una panorámica múltiple y compleja de los itinerarios sinuosos, opacos, por los cuales se cursa la revolución, ofreciendo una exposición y una reflexión notablemente más ricas de dicha realidad en el medium de su ficcionalización. El tratamiento desordenado que Yaroshevsky asume en "Escenas de la revolución rusa en provincia..." bien puede ser comprendido como un acercamiento a la revolución orientado a mostrar un estado de cosas contradictorio, lleno de aberturas y tensiones, donde el acontecimiento revolucionario se deja leer en el haz de motivos diversos y en confrontación que lo impulsan, y donde lo que se pierde en claridad conceptual se gana en palpitación de la dinámica de la revolución. Es decir, una estrategia cognoscitiva emplazada en una dialéctica "en suspenso", sin superación, que obliga al lector al acto interpretativo propio.

\footnotetext{
28 Ibíd., p. 464.

29 Ibíd. p. 468.

3o Ibíd. p. 469.

${ }^{31}$ Para esta idea del soviet como forma y contenido, como modo de la política revolucionaria, como denominación de la subjetivación emancipatoria, véase PITTALUGA, Roberto, Soviets en Buenos Aires..., ob. cit.
} 
El conjunto de los textos que produjera Yaroshevsky sobre la revolución rusa y que publicara en distintos medios de la Argentina constituye un fragmento, ciertamente de los más destacados, de aquellas lecturas realizadas desde tierras rioplatenses que se caracterizaron tanto por su agudeza interpretativa como por la movilización de un pensamiento político de gran riqueza. Aunque los emigrados rusos contaran con canales alternativos de información que permitían evitar los cables de las agencias monopólicas capitalistas, resulta igualmente notable esa potencia interpretativa desde "esta lejanía". Más interesante que adscribir sus textos a cierta lucidez personal - que ciertamente poseía - es pensarlos como emergentes y expresivos de ciertas relaciones que se tramaban en un campo de izquierdas políticamente multipolar - uno de tales polos era, precisamente, la posición de emigrado.

De vuelta en una Rusia ya soviética, no sabemos si este militante comunista continuó escribiendo desde estos ángulos. Las pocas líneas biográficas que Víctor Jeifets y Lazar Jeifets pudieron redactar lo colocan en ámbitos muy diversos, unidos por el lazo de la escritura: desde el departamento editorial de la Internacional Campesina, a la Universidad Comunista de los trabajadores de China; desde la OGPU o la Sección de Prensa del Ministerio de Relaciones Exteriores a desempeñarse como maestro y periodista en Alemania, Francia, Suiza y América, o como censor en el correo central de Moscú. $3^{2}$

\section{Anatol Gorelik y el fracaso revolucionario}

En 1922, con 32 años, Anatol Gorelik, luego de una breve estancia en Berlín, desembarcó en Buenos Aires, donde finalmente se radicó hasta su muerte en 1956, tras 16 años de postración debida a una parálisis. No era la primera vez que se había visto obligado a abandonar su Ucrania natal; perseguido por la policía zarista, entre 1909 y 1911 debió radicarse en Francia, y entre 1913 y 1917 en Estados Unidos, lugares donde continuó sus actividades militantes. En ambas oportunidades pudo volver a su tierra, pero de su último exilio, no podrá ya retornar. Detenido por los bolcheviques, primero en noviembre de 1920 y luego en marzo del año siguiente, su liberación junto a otros anarquistas - fue fruto de la presión ejercida por los propios detenidos

32 JEIFETS, Lazar; JEIFETS, Víctor, América Latina..., ob. cit., p. 66o; los autores no consignan la fecha de su fallecimiento. 
mediante una huelga de hambre y de los reclamos, simultáneos, que realizaron por los presos políticos los delegados de la III Internacional que se encontraban en Moscú.33

Entre 1917 y su detención, Gorelik se desempeñó como una de las principales figuras del movimiento revolucionario en Ucrania, ya fuera como miembro del Buró de los anarquistas de la cuenca del Don, como editor de la revista La voz del anarquista, como secretario de los grupos anarquistas Nabat o como integrante del Comisariado Popular de Educación en Ucrania. $34 \mathrm{Al}$ momento de su arribo a Buenos Aires, la mayor parte de la militancia ácrata ya había tomado distancia del rumbo de la revolución en Rusia, y las simpatías y renovadas expectativas que promoviera inicialmente se habían convertido, para 1921, en desilusión y crítica virulenta.35 Desde su llegada, Gorelik mantuvo una intensa actividad, sumándose a las filas libertarias y a la colectividad de inmigrantes rusos y ucranianos; esa labor se tradujo, entre otras cosas, en la publicación de diversos artículos y folletos destinados a exponer las características de la revolución y su rumbo actual a partir de su

33 Cfr. el relato del mismo GORELIK, Anatol, "Los anarquistas en la revolución rusa", en MINTZ, Frank (comp.), Anatol Gorelik. El anarquismo y la revolución rusa, Buenos Aires/La Plata, Libros de Anarres/Terramar, 2007, pp. 126-29. Puede también consultarse la breve biografía realizada por Frank Mintz, "Anatol Gorelik", en TARCUS, Horacio, Diccionario biográfico de las izquierdas argentinas. De los anarquistas a la "nueva izquierda" (1870-1976), Buenos Aires, Emecé, 2007, pp. 284-86. Sobre la liberación de los presos, véase también PESTAÑA, Ángel, Memoria que al Comité de la Confederación Nacional del Trabajo presenta de su gestión en el II Congreso de la III Internacional, Madrid, Nueva Senda, 1921. Quien esté interesado en la trayectoria de Gorelik, además de la citada biografía de Mintz, también puede consultar el artículo de JEIFETS, Lazar S. y ANDREEV, Anton S., "A. Gorelik: Argentinean touches of Russian Revolution Portrait", Bylye Gody, Sochi State University, 2015, Vol. 36, Is. 2, pp. 394-402; en este texto, los autores reconstruyen principalmente el recorrido político de Gorelik en el exilio, como también aportan datos básicos sobre la Federación de Organizaciones de Trabajadores Rusos de América del Sur a la que Gorelik se vincula, sobre el trabajo del ucraniano como editor y articulista del periódico Golos Truda y las posteriores colaboraciones con la española Revista Blanca en los años '3o y su papel como divulgador de las obras de los grandes referentes teóricos del anarquismo. De todos modos, si bien los autores presentan aspectos de las posiciones de Gorelik en relación a la revolución en Rusia, sus duras críticas al bolchevismo, al derrotero que toman los acontecimientos y al Estado soviético, no avanzan en un análisis de las mismas. Algunos de los manuscritos y papeles personales de Gorelik se han conservado en el Centro de Documentación e Investigacion de la Cultura de Izquierdas en la Argentina (CeDInCI), donados por su bisnieto, Diego Lois.

34 MINTZ, Frank, “Anatol Gorelik”, ob. cit.

35 Véanse PITTALUGA, Roberto, "Lecturas anarquistas de la revolución rusa", en Prismas. Revista de Historia Intelectual, Universidad Nacional de Quilmes, $\mathrm{n}^{0}$ 6, 2002, pp. 179-188; PITTALUGA, Roberto "De profetas a demonios: recepciones anarquistas de la revolución rusa. Argentina, 1917-1924", en Sociohistórica. Cuadernos del CISH, $\mathrm{n}^{0}$ 11/12, Facultad de Humanidades y Ciencias de la Educación, Universidad Nacional de La Plata, primer y segundo semestre de 2002, pp. 69-98; PITTALUGA, Roberto, Soviets en Buenos Aires, ob. cit. Incluso entre los llamados "anarcobolcheviques" la mayoría se muestra crítica del gobierno soviético y se aleja del pequeño grupo que mantendrá su apoyo; cfr. DOESWIJK, Andreas, Los anarco-bolcheviques rioplatenses, Buenos Aires, CeDInCI Editores, 2014; PITTALUGA, Roberto, Soviets en Buenos Aires, ob. cit. 
experiencia personal.

También para este revolucionario ucraniano la revolución fue obra de las masas populares, pues "el control obrero en las ciudades y la apropiación de las tierras en el campo fue realizado por los obreros y campesinos mismos”, 36 y en febrero de 1917 "la revolución rusa no fue guiada por nadie", pues "nadie obedecía ya, la iniciativa estaba en todos". 37 Se trataba, agrega en otro momento, de una revolución sin centro, que afloraba en diversos lugares simultáneamente. ${ }^{8} \mathrm{El}$ autor ejemplifica la expansividad revolucionaria, sobre todo en esa Ucrania que conoce con hondura, la cual se evidenciaba en el surgimiento de múltiples organizaciones caracterizadas por un protagonismo popular de talante autonomista. Precisamente, ese autonomismo se manifestaba cuando, luego de haber realizado la "obra profunda" por la cual la tierra pasaba a sus manos, esos mismos campesinos tenían que resolver "cómo vivir ahora sin la nobleza y sin policía”, cómo "organizarse fraternalmente para que todos pudieran vivir bien".39 Gorelik se propone demostrar las tendencias antiestatales y comunistas de la revolución:

\footnotetext{
"Podría dar varias centenas de ejemplos y de hechos que mostrarían el estado de espíritu de los campesinos revolucionarios, progresista y de clara tendencia comunista antiestatal (...) En numerosos pueblos, los campesinos daban el paso hacia principios de vida comunal. Las masas, por supuesto, no se organizaban en comunas completas, sino en arteles, en cooperativas en una palabra, en múltiples organizaciones de apoyo mutuo".40
}

Más allá de los avances y retrocesos, de las dificultades y los errores, el rumbo autonomista, autogestionario era fácilmente identificable, pues "las masas aspiraban instintivamente, y más o menos conscientemente, a una sociedad diferente, libre, sin patrones, ni capitalistas, sin propietarios ni gobierno, sin autoridad”. ${ }^{41}$ Para ello, para

${ }^{36}$ GORELIK, Anatol, "Los anarquistas... ”, ob. cit., p. 101. Este texto de Gorelik, originalmente escrito en Berlín, fue impreso en lengua rusa en Buenos Aires con el título "La emancipación de los trabajadores es la obra de los mismos trabajadores" por la editorial Golos Truda, en junio de 1922. Posteriormente, una versión con algunas diferencias, fue publicada por entregas en La Antorcha, del $\mathrm{n}^{0} 157$ (24/04/1925) al no 173 (14/o8/1925). Citamos aquí de la versión editada por Mintz.

37 Ibíd., p. 99. La importancia de estas afirmaciones sobre el protagonismo central del pueblo sólo es apreciable si se la observa en el campo de debates en la izquierda rioplatense en torno a los sujetos de la revolución en Rusia; cfr. el capítulo "Sujetos" en PITTALUGA, Roberto, Soviets en Buenos Aires..., ob. cit., pp. 163-215.

${ }^{8}$ GORELIK, Anatol, "El movimiento revolucionario de las masas en Ucrania", en MINTZ, Frank, Anatol Gorelik..., ob. cit., pp. 141-169. El texto fue publicado originalmente en junio de 1924.

39 GORELIK, Anatol, "Los anarquistas...", ob. cit., p. 103.

40 Ibíd.

${ }_{41}$ Ibíd., p. 116. En otra parte sostiene: "El pueblo buscaba a tientas, erraba y aprendía a la ligera la manera de encontrar de cualquier modo la salida de la situación que se había creado y para poder construir una convivencia nueva, de bienestar y de dicha para todos los hombres. Las masas 
"encontrar el verdadero camino de la liberación del yugo del Estado y de la explotación", las emergentes organizaciones de las masas reemplazaban "el capitalismo por la comunización y la cooperativización voluntarias", y al Estado "por libres y voluntarios acuerdos" y por "la descentralización de las funciones sociales".42

Entre los obreros de las ciudades un mismo "trabajo profundo había tenido lugar", de modo que ese espíritu también se verificaba, e incluso se mantuvo cuando la represión bolchevique desarmó el poder obrero en las unidades fabriles; los obreros, relata Gorelik, abandonaron las empresas estatalizadas para crear otras organizaciones en el espacio productivo, y resistieron la ofensiva gubernamental: "Hubo millares de huelgas (...) desencadenadas contra la voluntad de los sindicatos estatales y de los soviets bolchevizados (...) a menudo acabadas con la ametralladora". 43 Situación que se repite con "las diferentes organizaciones culturales [que] fueron igualmente tomadas en mano por el Estado". Frente al poder estatal, los trabajadores crearon "pequeños clubes ilegales" que incluso "atrajeron a obreros comunistas", clubes improvisados que exhibían los ímpetus y capacidades organizativas de las clases populares. 44

Esta última apreciación resulta importante. Gorelik ubica lo que llama tendencias o actitudes anarquizantes más allá de las identidades asumidas por obreros, campesinos, etc.. Por ello menciona que algunos comités obreros del Partido bolchevique fueron "totalmente compuestos de trabajadores anarquizantes". $45 \mathrm{O}$ que, en 1920, "en un congreso de la juventud ucraniana, el $35-37 \%$ de los delegados resultaron anarquizantes" ${ }^{46}$ Lo que quiere mostrar es esa extensión de un espíritu expresivo de la autoconstitución del pueblo, un espíritu emergente directamente de las filas populares cuando éstas se organizan por su cuenta, sin mediaciones; y justamente por dicha característica, dotado de potenciales capacidades para constituir una nueva forma de vida común, sin explotación ni dominación.

caminaban hacia la revolución social a pasos agigantados. Superaron a todos los partidos políticos, inclusive los más izquierdistas", GORELIK, Anatol, "El anarquismo y la revolución rusa", en MINTZ, Frank, Anatol Gorelik..., ob. cit., p. 34.

${ }^{2}$ Ibíd., p. 35.

43 GORELIK, Anatol, “Los anarquistas...”, ob. cit., p. 117.

44 Ibíd., pp. 117-18.

45 Ibíd., p. 117.

${ }^{46}$ Ibíd., p. 118; el énfasis es mío. Toda la juventud debió adherirse a la Unión de la Juventud Comunista si pretendía tener locales y apoyo financiero, explica Gorelik. 
Anarquizante es, así, una etiqueta para nombrar un arco de acciones y formas de subjetivación autonomistas, y tendencialmente anarquistas en la revolución. 47

Gorelik elige cuidadosamente: las tendencias de las masas en Rusia son anarquizantes, pero no anarquistas -o no aún. $4^{8}$ Por eso afirma que "en Rusia no hubo revolución social, ni antes ni después de Octubre”.49 Sus textos no se orientan como en Yaroshevsky - a explicar el surgimiento de la revolución, sino su declive, su derrota, su fracaso. En un punto, ese fracaso se explica por su no consumación plena, por su carácter incompleto; y si bien nuestro autor va a dedicar varias intervenciones, a lo largo de la década de 1920, a reflexionar sobre los motivos de ese fracaso, ya desde sus primeros textos apunta ciertos límites para aquella tentativa insurreccional: "la revolución rusa ha derrocado al gobierno zarista, destruido todas las antiguas bases sociales, abolido el poder económico de los capitalistas y terratenientes y se ha puesto en las vías de construcción de una vida social nueva”, pero como todos los movimientos sociales previos "pudo dar y cumplir solamente aquello de que fueron capaces las masas populares de Rusia y en la medida en que estuvieron preparados ideológica y moralmente sus elementos avanzados”.50

La ausencia de experiencia histórica de largo plazo, la confluencia en el movimiento revolucionario de ideologías distintas y aun antagónicas, fueron factores que impidieron la plena realización de la revolución como "revolución social". Entre todos esos factores, Gorelik destaca, por un lado, lo que considera el oportunismo bolchevique, que adopta la "etiqueta comunista" y las ideas antiestatalistas y antiautoritarias del anarquismo a fin de interpelar exitosamente a las masas, provocando una verdadera captura de las ideas libertarias. Por otro lado, la defección de muchísimos anarquistas, seducidos por el llamamiento bolchevique. ${ }^{51}$ Una fascinación "por las palabras escritas en la bandera roja" que condujo a que "la mayor parte de los militantes anarquistas" colaboraran "con los bolcheviques en las

\footnotetext{
47 La nominación no es inocente, pues mientras relega las otras identidades políticas revolucionarias, produce una identificación entre anarquía y revolución. Pero lo que interesa retener aquí, más allá de cómo las denomine Gorelik, es esta observación sobre la existencia, expansividad y ubicuidad múltiple de acciones y subjetivaciones autonomistas como aspecto esencial de la revolución en Rusia.

48 GORELIK, Anatol, “El anarquismo y la revolución rusa”, ob. cit., p. 42.

49 Ibíd., p. 102.

5o GORELIK, Anatol, "El anarquismo y la revolución rusa”, ob. cit., p. 33.

$5^{1}$ "...las frases altisonantes de Lenin y otros socialdemócratas trastornaron la cabeza a muchos anarquistas (...) Algunos anarquistas empezaron ya a hablar de integrar el Partido Comunista", GORELIK, Anatol, "Los anarquistas...", ob. cit., pp. 100-01.
} 
instituciones gubernamentales, aunque seguían criticando el estatismo centralizador". ${ }^{2}$ Si para Gorelik las masas en Rusia se habían movilizado en sentido anarquizante, la ausencia de un frente unido anarquista que potenciara esas tendencias estimulándolas, colaborando en el desarrollo de sus fuerzas y aspiraciones, ofreciendo los análisis necesarios, aportando soluciones libertarias frente a los obstáculos, profundizando la conciencia anarquista, ayudando a la formación teórica de las jóvenes generaciones de activistas, constituyó una de las principales causales del fracaso revolucionario. A pesar de la resistencia del propio movimiento autónomo de masas a ser disciplinado por el nuevo Estado, que Gorelik ejemplifica en la consigna "Todo el poder a los soviets, no a los partidos" 53 , la inmadurez e inexperiencia del movimiento revolucionario de masas y la dispersión o el desvío del activismo anarquista no pudieron evitar la imposición de un curso autoritario y estatalista para ese gran experimento revolucionario. 54

El "trastorno" que para Gorelik habrían causado las ideas marxistas y de la socialdemocracia rusa en el ideario y la actividad de los anarquistas se convierte en un tema relevante de sus intervenciones y publicaciones. Este enfoque habilita un rescate del ideario anarquista como tal, escindiéndolo de las versiones bolchevizadas, politizadas, en que habrían recaído gran número de libertarios. Pero eso es sólo una parte de sus propósitos. Paulatinamente, en sus escritos sobre el tema, esta corrupción del anarquismo va convirtiéndose en uno de los argumentos principales de su explicación del derrotero de la revolución: el marxismo habría producido una “desnaturalización” del anarquismo, distorsionando gran parte de los conceptos fundamentales de la tradición libertaria.55 Sin embargo, subsisten dos preguntas: ¿por qué motivos los anarquistas habían podido ser seducidos y corrompidos por el marxismo y el bolchevismo? Y, más aún, ¿cómo había sido factible para los "marxistas autoritarios" hacer pie en una revolución donde las masas exhibían sus tendencias anarquizantes? La respuesta a ambos interrogantes la encuentra en que "el marxismo es una idea que no tiene base moral, ningún ideal ético" y es por ello

${ }^{2}$ Ibíd., p. 105.

53 GORELIK, Anatol, “El movimiento revolucionario ...”, ob. cit., p. 161.

54 Gorelik no dudaba sobre el significado mayor para la historia que tenía la experiencia revolucionaria de las masas en Rusia, antes de que fuera cerrada por la disciplina estatal, y por eso nos ha dejado una tarea: "Esta fue la época más maravillosa y más bella de la revolución rusa. El futuro historiador, inevitablemente, tendrá que detenerse mucho sobre estos acontecimientos de la revolución"; GORELIK, Anatol, "El anarquismo y la revolución rusa", ob. cit., p. 35.

55 Cfr. GORELIK, Anatol, “Los anarquistas...”, ob. Cit. 
que puede adaptarse "tan fácilmente a todas las circunstancias". ${ }^{6}$ Esta ausencia de principios morales, continúa el ucraniano, posibilitó a los bolcheviques aceptar, de palabra, la revolución social, mientras de hecho instauraban "su política y su programa de partido político, aprovechándose del desconocimiento por parte de las masas de los problemas, el sentido y el significado de la Revolución Social”.57

Más allá de las acusaciones hacia Marx, Lenin y los marxistas por carecer de principios éticos ${ }^{8}$, resulta interesante detenerse en esta preocupación por la moral y/o la ética de la revolución.59 Gorelik observa la deriva de la revolución en Rusia cotejándola con la insurrección de la Comuna parisina de 1871: ambas se malograron por su impericia para crear un nuevo mundo moral-como expusieron al examinarlas algunas de las figuras mayores de la tradición libertaria, como Bakunin, Malatesta y Kropotkin.6o Este último habría visto y vivido en "el fracaso del experimento ruso" un aspecto más determinante que la dictadura bolchevique o las formas institucionales en que finalmente encarnó la revolución: tal elemento lo encontró "en el fundamento básico que sostiene cualquier convivencia humana: la ética de los hombres que la componen". ${ }^{61}$ Si Kropotkin escribió una Ética a partir de la frustrada revolución rusa, y Bakunin se habría abocado a una tarea similar que finalmente no concretó a propósito de la Comuna, es porque, colige Gorelik, del fracaso ellos extrajeron una experiencia $-\mathrm{y}$ un mandato, podríamos agregar-: que "una revolución que no crea nuevos valores morales y éticos y que no trae consigo nuevos y más elevados principios morales, no puede ser una revolución social”. ${ }^{62} \mathrm{El}$ factor fallido habría sido que "las masas agitadas por la revolución, carecieron del

${ }^{56}$ GORELIK, Anatol, "El anarquismo y la revolución rusa", ob. cit., p. 47.

57 GORELIK, Anatol, La Revolución Social, Buenos Aires, Ediciones del Ateneo Anarquista, 1923, p. 18.

58 “... todo el marxismo está compuesto de contradicciones, y el amoralismo y el antihumanismo pasa como una línea roja bien trazada por toda su actividad práctica", GORELIK, Anatol, "El anarquismo...", ob. cit., p. 46.

59 Nuestro autor hace, por momentos, un uso indistinto entre los términos "moral" y "ética".

6o GORELIK, Anatol, “El anarquismo...”, ob. Cit., pp. 49-51.

61 GORELIK, Anatol, "Las causas del fracaso de la revolución rusa", en Pampa Libre. Periódico quincenal anarquista, $\mathrm{n}^{\circ}$ 109, Santa Rosa, La Pampa, 20 de julio de 1927, p. 9. Aunque "como socialista estaba impregnado de pensamientos e ideas socialistas en las que el elemento social prevalecía en mucho sobre el elemento individual o personal”, Kropotkin pudo apreciar las causas del fracaso "con su vista penetrante y experimentada de hombre de ciencia"; íbidem. Este texto de Gorelik se publicó en el periódico libertario Pampa Libre en 15 entregas entre el 15 de septiembre de 1926 ( ${ }^{\circ}$ 94) y el 19 de febrero de 1928 ( $\left.\mathrm{n}^{\circ}{ }^{117}\right)$; en cada cita consignaremos el número del periódico y la fecha de publicación.

62 GORELIK, Anatol, “El anarquismo...”, ob. cit., p. 49. 
fundamento esencial para poder crear una base estable y humana en la obra de reconstrucción social", ${ }^{63}$ pues aun la mayoría de "los hombres que se llaman revolucionarios y comunistas" carece "de una idea moral orientadora, de un ideal moral elevado". Y apoyándose en Kropotkin, afirma que "sin duda por la ausencia de este ideal moral elevado, la revolución rusa se mostró impotente para crear un nuevo orden social sobre bases de justicia y de libertad". ${ }^{64}$

La convivencia humana así como los continuos esfuerzos por mejorarla residen, asegura apelando a Bakunin y Kropotkin, en un conjunto de instintos que son "hábitos hereditarios arraigados", instintos como los de mutualidad y solidaridad, y también "el instinto moral". ${ }^{6}$ Como estos tres componentes -la ayuda mutua, la solidaridad y la moralidad- en tanto "instintos naturales" son inmanentes a cualquier convivencia que quiera progresar; "el fracaso de la revolución rusa”, más que provenir de las políticas económicas $-\mathrm{o}$, precisamente, por intentar reconstruir la sociedad humana sobre bases económicas - fue el inevitable resultado de la ausencia de una moral orientadora. ${ }^{66}$ De modo que la enseñanza principal de la revolución rusa que Gorelik llama a atesorar para futuras experiencias se puede resumir del siguiente modo: una revolución sólo triunfará cuando "la ética reemplace a la política y la solidaridad a la concurrencia económica", evitándose así "toda coerción e imposición en la convivencia humana”.67 En el universo conceptual anarquista, la oposición entre ética y política remite a aquella entre autonomía y heteronomía, entre libre cooperación y coacción; de modo que el argumento sobre la moral refiere, entonces, a una problemática que no puede explicarse meramente por una suerte de cinismo o manipulación bolchevique de masas sin la suficiente madurez o de vanguardias - anarquistas - sin una ética lo suficientemente arraigada. La cuestión remite directamente a las características de los órganos de la revolucíon, a esas formaciones de las masas revolucionarias - sean los soviets o las comunas campesinas, el ejército makhnovista o los comités de fábrica- y a sus capacidades o incapacidades para promover otra forma de "convivencia humana" que fuera adecuada al despliegue de las potencialidades de los hombres y las masas. Nuestro

\footnotetext{
63 GORELIK, Anatol, "Las causas...", ob. cit., nº 110, 5 de agosto de 1927, p. 9.

64 Ibíd. Énfasis en el original.

${ }_{65}$ Ibíd., nº 109, 20 de julio de 1927, p. 9.

66 Ibíd.

${ }_{67}^{6}$ Ibíd. no 117, 19 de febrero de 1928, p. 10.
} 
autor indica que una revolución será realmente triunfante cuando además de resolver "las cuestiones del trabajo, de la economía y de la emancipación obrera", implante nuevos modos y fundamentos del mundo común, los cuales precisan, para formularse, de otorgar "un libre juego a las iniciativas de las masas y de los hombres para que la convivencia humana surja como una consecuencia de la libre colaboración de todos los hombres, de su conciencia y sus deseos y de una moralidad más elevada de bienestar común e individual”. ${ }^{68}$ El peligro mayor, advierte Gorelik citando a Alexandr Moisievitch Atabekian, consistiría "en la poca escrupulosidad moral de los medios". ${ }^{69}$ La moral, la ética en la que debe sostenerse una revolución parece resolverse en la adecuación entre medios y fines: a los elevados fines de emancipación de los oprimidos y de la humanidad toda le corresponden, sostiene, medios que expandan las potencias y capacidades de todos y cada uno de los individuos. $7^{0}$ Así, nuestro autor abre una senda hacia otra forma de intelección de las relaciones medios/fines, cuestión de enorme importancia a la hora de aprehender los rasgos más radicales de la revolución en Rusia.

Gorelik escribe de modo urgente. Escribe porque le apremia dar a conocer la situación en Rusia, pero también explicar (y explicarse) la derrota, su cárcel y exilio, la debacle del poder autónomo de los soviets y las masas en Ucrania - y en toda Rusia-, la eliminación de las disidencias políticas con y al interior mismo del bolchevismo. Escribe proveyendo a los lectores de información sobre el complejo panorama político en Rusia -dando cuenta de la diversidad de grupos revolucionarios y de tendencias al interior de esos mismos grupos ${ }^{71}$ Escribe también por un compromiso con sus camaradas en Rusia, muchos de ellos muertos en la guerra civil y muchos otros ejecutados en las cárceles bolcheviques. ${ }^{72}$ Escribe, asimismo, para sus camaradas futuros, para quienes no conocerá, a quienes quiere

\footnotetext{
68 Ibíd., nº 110, 5 de agosto de 1927, p, 9.

69 Ibíd., $\mathrm{n}^{\circ} 117,19$ de febrero de 1928, p. 10.

70 Ibíd. Cfr. también GORELIK, Anatol, "El anarquismo y la ética (segunda parte)", en La Antorcha, no 125, Buenos Aires, 28 de marzo de 1924, p. 3.

${ }^{71}$ Véase al respecto la descripción de grupos y tendencias en torno a distintas problemáticas en "Las causas...", ob. cit.

$7^{2}$ Véanse la serie de semblanzas biográficas que publica en La Antorcha: GORELIK, Anatol, “A. M. Atabekian”, La Antorcha, ${ }^{0}$ 128, Buenos Aires, 18 de abril de 1924, pp. 2-3; GORELIK, Anatol, "Aron Baron", La Antorcha, $\mathrm{n}^{\circ}$ 129, Buenos Aires, 25 de abril de 1924, pp. 2-3; GORELIK, Anatol, "Lewa Kogan", La Antorcha, no 130, Buenos Aires, 2 de mayo de 1924, pp. 2-3; GORELIK, Anatol, "Fanny Baron", La Antorcha, no 131, Buenos Aires, 16 de mayo de 1924, p. 2; GORELIK, Anatol, "Voladia Poteckin", La Antorcha, no 132, Buenos Aires, 23 de mayo de 1924, pp. 2-3.
} 
dejarles su testimonio. Escribe, por momentos, de modo aleccionador, de forma taxativa, eliminando los matices, disolviendo la complejidad en trazas nítidas que pongan en el primer plano de visibilidad las líneas de fuerza de la revolución y sus confrontaciones, sus posibilidades y límites. Escribe convencido de que la enorme expectativa que para la humanidad emergió en Rusia está a punto de desplomarse completamente, y a pesar de ello hay que extraer de allí experiencias.

Cierta precipitación y la necesidad de hacer oír otras voces, hacen que sus razonamientos deriven, en no pocas ocasiones, hacia simplificaciones poco productivas; como cuando los fundamentos morales de una nueva comunidad humana terminan afirmándose en una individuación aparentemente preexistente a todo lazo, lo que extremiza su anarquismo de sesgo individualista.73 Otros textos ofrecen una mirada equilibrada, capaz de valorar positivamente algunos aspectos sin eludir la crítica de otros, como, por ejemplo, aquellos artículos dedicados a evaluar las reformas educativas de la revolución. 74 En otros pasajes, la acusación sustituye a la crítica, y el comentario se convierte en una descalificación sin una evaluación más profunda de la problemática.75 Notablemente, ciertas reflexiones que permitirían reformular su comprensión de las formaciones revolucionarias de las masas atendiendo a su carácter de subjetivaciones políticas -como cuando intuye que las identidades sociales preexistentes, como obreros o campesinos, no pueden agotar la "personalidad" de los individuos y las masas que actúan revolucionariamentequedan apenas expuestas, quizás para que otros, en el futuro, se sientan interpelados como para retomarlas. ${ }^{76}$

\footnotetext{
73 GORELIK, Anatol, "El anarquismo y la ética...”, ob. cit.

74 GORELIK, Anatol, "La educación en la Rusia soviética (poder comunista y educación)", en MINTZ, Frank, ob. cit., pp. 173-180. Una versión traducida por Julio Company fue publicada en dos entregas con el título "La política educacional de los comunistas" en La Antorcha, Buenos Aires, $\mathrm{n}^{\circ} 167$ y 168 , los días 2 y 10 de julio de 1925, pp. 2 y 3 respectivamente.

$75 \mathrm{Al}$ criticar "toda imposición", Gorelik reprueba también "la idea de la dominación de la clase obrera", incluso en las versiones anarcosindicalistas rusas que se oponen a la dictadura del partido. A dicha idea la juzga no menos peligrosa que la dominación burguesa, de lo que desprende el carácter aporético del lema "todo el poder a los soviets" como instancias de emancipación humana, pues se trataría de configuraciones de poder proletario que se impondrían como dominio sobre "otros" que no fueran trabajadores. Cfr. GORELIK, Anatol, "El fracaso...”, ob. cit., y GORELIK, Anatol, “Anarquismo y «anarquismo obrero", en La Antorcha, no 135, Buenos Aires, 13 de junio de 1924, pp. 1-2. En este punto, Gorelik no percibe a los soviets como instancias de subjetivación, y sus censuras contrastan con los textos de Rudolf Rocker que por los mismos años publica La Protesta.

${ }^{76}$ Seguramente, parte de sus intervenciones - como puede inteligirse de sus textos- están destinadas a un campo anarquista rioplatense que ha exacerbado sus diferencias y sus intolerancias; el alineamiento de Gorelik, mayoritariamente con los denominados "antorchistas", y sus ásperos cruces
} 
En textos que son mayormente planos, como si formaran parte de una tarea educativa de corte ilustrado, igualmente Gorelik se hace un espacio para ilustrar su punto de vista sobre la relación medios/fines, a través de una experiencia singular de gran potencia política y figurativa. Relata que el 13 de febrero de 1922 se realizó, en Moscú, "el primer concierto sin director de orquesta”, una experiencia que desde entonces se había multiplicado. Evaluando la misma, el crítico musical de Izvestia, Antón Utgof, había aseverado que si bien la ejecución había sido "excelente, las entradas puntuales y ciertas”, notándose una "solidaridad familiar en los tiempos”, lo más destacable había sido que "durante la ejecución hubo momentos de [gran] inspiración en la masa orquestal arrastrada por el sentimiento de concordia y unanimidad creadora", momentos que "nunca se encuentran en un conjunto con batuta”. Relato a partir del cual el revolucionario ucraniano sostiene:

“... la realidad de los hechos les demostrará que con la ausencia de batutas directoras en la vida social se creará la verdadera y profunda armonía en la convivencia humana, donde la multiplicidad de las formas y la libertad de las experimentaciones sociales producirá una concordia y solidaridad esencialmente fecunda". 77

\section{Komin-Alexandrovsky: entre el retorno y la defensa}

Muy distinto de lo escrito por Yaroshevsky o Gorelik es lo que nos ofrece Komin-Alexandrovsky en su Impresiones de un Viaje a la Rusia Sovietista, publicado en Buenos Aires en 1921, primero como notas sucesivas en el periódico La Internacional y luego como folleto por la editorial del mismo nombre del novel Partido Comunista. ${ }^{8}$ Se trata de un texto en el que se superponen algunos de los tópicos del relato de viajes con la gramática del panfleto político; superposición que por tramos obra como potenciadora de esta última por la primera, pero en otros pasajes - pocos, es cierto- desgaja la unidad y certeza doctrinaria del texto.

Mijail Alexeevich Alexandrovsky, conocido mayormente como KominAlexandrovsky o Kolman, nació en Nizhny Novgorod en 1884, en el seno de una familia de trabajadores. Como señalan Lazar Jeifets y Víctor Jeifets, de muy joven se unió al Partido Social Demócrata Obrero de Rusia (PSDOR), mientras concurría

con Diego Abad de Santillán, seguramente también dejaron su marca en una producción textual con visibles ambivalencias, las cuales forman parte de su riqueza.

77 GORELIK, Anatol, "Las causas...", nº 117, 19 de febrero de 1928, p. 10.

78 ALEXANDROVSKY, Impresiones de un Viaje a la Rusia Sovietista, Buenos Aires, La Internacional, s/f. [1921]. En la tapa se aclara que se trata de una "Publicación Oficial de la Internacional Comunista (Sección Argentina)". 
como oyente a la Universidad Popular de su ciudad natal; su activismo revolucionario lo llevó a participar de la insurrección armada de 1905 en Sormov, y a vivir clandestinamente; capturado por las fuerzas zaristas, es condenado a prisión perpetua, pero logra escapar y emigrar, arribando a Buenos Aires en 1909.79 En la Argentina trabajó como mecánico, y continuó con sus actividades militantes integrándose al Grupo Socialista Ruso Avangard, vinculado al Partido Socialista. Desde 1912 despliega una prolífica labor militante como uno de los organizadores de la Federación de Obreros de los Ferrocarriles del Sud, colaborando en el "Comité de Ayuda a los exiliados políticos y trabajadores forzados", que desde 1917 pasa a denominarse "Comité de Ayuda a los Diputados obreros, soldados y campesinos", luego "Unión de los Obreros Socialistas Rusos" y finalmente Grupo Comunista Ruso. En 1918 integra el recién formado Partido Socialista Internacional, luego Partido Comunista. Komin-Alexandrovsky también se destacó como uno de los fundadores de la Federación de Obreros Rusos en Sudamérica (FORSA) y director de su periódico, Golos Truda; fue electo representante de FORSA para asistir al II Congreso de la Comintern en Moscú, en 1920.80

Impresiones de un Viaje a la Rusia Sovietista es un texto con una composición dual; como decíamos, se estructura sobre un doble registro narrativo. El título anticipa un contrato de lectura por el cual el autor ofrece una suerte de narración experiencial, es decir, una elaboración de ese conjunto de percepciones vividas al transitar por el territorio de la revolución, donde el elemento descriptivo es acompañado por el reflexivo, donde el relato factual se enriquece con el comentario. La primera parte del texto sigue esas modalidades; incluso se alimenta de uno de esos tópicos claves de la literatura de viajes, el del relato del recorrido y sus peripecias previas al destino, que en el caso de las travesías hacia las tierras de la revolución puede ser modulado en tonos cuasi épicos. ${ }^{81} \mathrm{El}$ tono intimista y de complicidad de las páginas iniciales ${ }^{82}$, el relato de las incidencias y desventuras que el autor y su familia

\footnotetext{
79 JEIFETS, Lazar y JEIFETS, Víctor, ob. cit., pp. 326-27. También TARCUS, Horacio, ob. cit., pp. 33940.

80 JEIFETS, Lazar y JEIFETS, Víctor, ob. cit.; TARCUS, Horacio, ob. cit.

${ }^{81}$ Para algunos de tales tópicos de la literatura de viajes, y en particular para los casos de viajeros argentinos hacia destinos revolucionarios, puede consultarse el prólogo de Sylvia Saítta, titulado "Hacia la revolución", en su compilación de textos de viajeros: SAİTTA, Sylvia, Hacia la revolución. Viajeros argentinos de izquierda, Buenos Aires, FCE, 2007, pp. 11-44.

82 "Como sabéis vosotros, compañeros..." son las palabra de apertura que elige; ALEXANDROVSKY, Impresiones..., ob. cit., 3 .
} 
- su esposa y sus hijos - deben afrontar en esos cuatro meses de viaje -incluyendo momentos al borde de la subsistencia-, los silencios que deben guardar si es que quieren atravesar esa frontera, y un realismo del detalle sitúan al lector frente a una narrativa marcada por la exposición subjetiva de su autor, una subjetividad que desde el inicio puede percibir los abusos, injusticias y humillaciones "del viaje" y de los lugares que se atraviesan "antes del destino", porque se afirma en un lugar político, también explicitado, desde donde observa. 83

Y, ciertamente, en esos primeros apartados, el autor recurre al tópico del atravesamiento de las fronteras, sólo que las que en este caso debieron superarse no constituyen solamente un límite político-administrativo, sino una frontera hecha de una mezcla específica de espacio y tiempo. Las descripciones de un mundo en decadencia, en donde la explotación y la opresión exponen desembozadamente su rostro, conforman el grueso de las "impresiones” de Komin-Alexandrovsky tanto en los navíos en que se traslada como, más aún, en las ciudades que son parada obligada, como Alejandría, el puerto de Pireo, Constantinopla, Crimea. En el relato, Constantinopla, además de ser el reducto de la contrarrevolución blanca que cuenta con el apoyo de las potencias capitalistas, materializa el pasado autocrático de la Rusia zarista: "La ciudad ofrecía un aspecto inimaginable; millares y millares de rusos fugitivos, entre ellos miembros de la antigua aristocracia y del clero, generales, coroneles y oficiales, capitalistas, estancieros, representantes de la administración e intelectuales (...) Todos formaban una masa informe de mendigos hambrientos", que orgullosos de su pasado de clase dominadora "se enrolaban como voluntarios en el ejército de Wrangel". ${ }^{84} \mathrm{El}$ cuadro que presenta no se restringe a la ex clase dominante: toda la ciudad muestra los signos de una sociedad degradada, pues "el alcoholismo y la prostitución se desarrollan en Constantinopla en forma jamás vista (...) los bailes desenfrenados de los ebrios, los escándalos a cada minuto, las peleas, la mendicidad, todo junto forman algo que no tiene nombre”. Y aunque sostiene haber

\footnotetext{
83 De las 40 págs. del folleto, las primeras cinco son dedicadas al viaje hasta territorio bajo control del gobierno soviético. Determinados giros en el relato, como cuando recuerda su llegada a Nizhny Novgorod, donde "permanecimos con mi familia un día, no obstante tratarse de mi pueblo natal y en el que transcurrió mi infancia" implicaban compartir cuestiones personales con sus camaradas de militancia en Buenos Aires , muchos de ellos también exiliados rusos; ALEXANDROVSKY, Impresiones..., ob. cit., p. 11. Para 1925, la Asociación Amigos de Rusia estimaba en más de 100.000 los inmigrantes provenientes de alguna de las regiones que formaban parte de la URSS y que residían en Argentina; cfr. "Pidiendo el reconocimiento de Rusia" (1925), en Revista de Oriente, $\mathrm{n}^{\mathrm{o}}$ 2, julio, p. 28.
}

84 ALEXANDROVSKY, Impresiones..., ob. cit., p. 5. 
visto, en Grecia, en Egipto, en las Islas de Cabo Verde "escenas que hacen estremecer de indignación: las gentes, como perros, se disputan un pedazo de pan tirado desde a bordo del buque", afirma también que jamás había visto "lo que sucede en Constantinopla ... bajo la protección de las «grandes potencias civilizadas»". 85

Este mundo del pasado de la explotación es el que antecede en el viaje -y en la historia, según nuestro autor- a la tierra liberada, de modo que la travesía es presentada a su público rioplatense como un viaje a Rusia y también como un viaje al futuro emancipado. Pero además, y espacialmente, atravesar esa frontera implica pasar por el territorio de la guerra, por esos márgenes del territorio "europeo" Crimea, Grecia, el ex Imperio Otomano- que exponen más nítidamente el carácter de guerra civil, como sostiene Enzo Traverso, de la Gran Guerra y sus continuidades. En casi todos estos lugares, "los soldados del ejército de ocupación", apunta KominAlexandrovsky en referencia a blancos y aliados, llevan a cabo "una actividad febril; se cargan, se descargan los materiales bélicos procedentes de los civilizados pueblos de Europa y América; y todo contra la Rusia de los obreros y campesinos, y contra Turquía, casi destruida, pero que sigue combatiendo por su existencia".86 Paradójicamente, trasponer esas divisorias espacio-temporales para llegar a la tierra liberada exige, durante el recorrido, navegar en un buque que porta un "pabellón tricolor, símbolo de un imperio que [ya] no existía"; guardar silencio frente "a esas patrañas tan bajas, tan estúpidas, inventadas contra el nuevo orden social", "esas narraciones de inimaginables horrores del régimen bolcheviki" que publicaba la prensa burguesa; y fingir simpatías con la contrarrevolución, ponerse una máscara y ocultar las expectativas revolucionarias.

$\mathrm{Si}$, como sostiene Mary Louise Pratt, las "escenas de arribo" son un tópico de la literatura de viajes en la medida en que estructuran el intercambio intercultural y fijan los marcos de su representación ${ }^{87}$, nuestro autor construye ese nuevo país de los Soviets en contraste, tanto con las escenas del viaje relatado, como con las realidades políticas, sociales, culturales de las clases subalternas en Argentina y Latinoamérica. El primer contraste es el trato: si para llegar a Rusia debió trabajar en varias ciudades, gestionar por su cuenta hospedajes apenas habitables y obtener, cada vez,

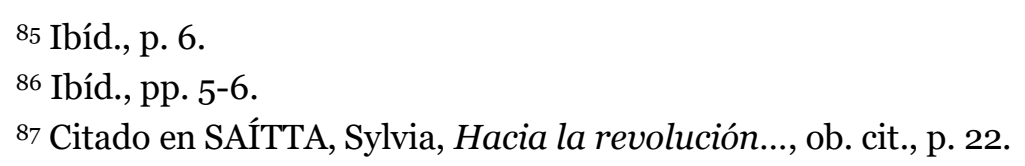


los papeles necesarios exigidos por distintas burocracias, en las distintas ciudades soviéticas lo que prima es la colaboración y la ayuda, de obreros y soldados, de funcionarios de los órganos del gobierno soviético.

Komin-Alexandrovsky configura esas "escenas de arribo" a partir de impresiones de incredulidad, lo que realza el contraste entre vieja y nueva sociedad, entre subjetividades del pasado y del futuro: "Era un domingo (...) En una calle me asombré al encontrarme con un grupo armado de palas y escobas, ocupado activamente en la limpieza, acompañados por los carros de basura (...) hombres y mujéres, jóvenes en su mayoría"; a pesar de las explicaciones que los propios trabajadores le sumistran "yo me resistía a comprenderles, porque no concebía una fiesta con palas y escobas"; y concluye nuestro autor que "los comunistas emplean las horas que les sobran en trabajos comunales, sin percibir por ellas remuneración alguna". ${ }^{88}$ La incredulidad modula el contraste sin nombrarlo, apelando a los saberes de quienes habitan las realidades del capitalismo periférico, y también se aferra a los saberes de las utopías sociales, para presentarlas como si estuvieran en proceso de realización.

Este diseño le permite a Komin-Alexandrovsky ofrecer una panorámica de la vida económica, social, política y cultural de Moscú, ya vertebrada sobre distintos planos de contraste con aquella otra del obrero en el universo capitalista. Así, desfilan distintas temáticas: una jornada de trabajo de 7 horas en fábricas y talleres, pautada de 9 a 17 "con un intervalo para la comida" en comedores comunes, 89 el abastecimiento de vituallas garantizado según prioridades (los niños y el Ejército Rojo, en primer lugar; seguidos de trabajadores, sus familias y finalmente ex miembros de la antigua clase dominante), ${ }^{\circ 0}$ las mujeres trabajadoras dejando a sus hijos en guarderías habilitadas en las fábricas y talleres, ${ }^{11}$ el reparto gratuito de "la ropa, tanto la de trabajo como la común y la especial (en ciertos oficios)", incluyendo "el calzado y la gorra", más implementos de limpieza personal,92 los niños educándose porque no trabajan hasta los 16 años,93 las viviendas otorgadas "por

\footnotetext{
88 ALEXANDROVSKY, Komin, ob. cit., p. 11.

89 Ibíd., p. 15.

90 Ibíd., p. 15.

${ }^{11}$ Ibíd., p. 16.

92 Ibíd., p. 15.

93 Ibíd., p. 16.
} 
intermedio de la comisión de tierras y viviendas del Soviet de diputados obreros"; el racionamiento mediante el sistema de tarjetas, con los incentivos materiales a la productividad cada vez más extendidos;94 las vacaciones anuales de 30 días en las "casas de reposo"; los jardines de infantes, las colonias y la educación garantizada para todos los niños.95 Todos estos señalamientos e informaciones proponen un cuadro de situación en el que, a pesar de la guerra y el bloqueo, la Rusia Soviética se orientaría según parámetros igualitaristas y de garantía de derechos básicos.

Un cuadro complementado, a su vez, por algunos pasajes en los que se pinta la vitalidad urbana moscovita y la nueva actividad cultural, como cuando el autor anota el aspecto "bastante animado de las calles de Moscú", con su circulación de "coches de alquiler y de los carros de carga", o de "los automóviles [que] corren en todos sentidos"; o al señalar el funcionamiento a pleno de "todos los teatros y en mayor cantidad que antes", pues se han organizado "muchas compañías de aficionados que brindan sus espectáculos en edificios adecuados", mientras continúan las puestas de grandes obras en los teatros oficiales, con el elemento adicional de que las entradas se reparten proporcionalmente entre los sindicatos posibilitando el acceso a los mismos de sectores que hasta entonces habían sido excluidos. Del mismo modo, museos y otras entidades culturales son desde la revolución, de acceso libre y gratuito, mientras numerosos trabajadores y trabajadoras se suman a los diversos cursos (de idiomas, $o$ de distintas materias), brindados por los sindicatos. 96

Si bien Komin-Alexandrovsky no oculta ni niega las dificultades -la escasez de carne, que no vaya al frente de guerra,97 el estado deplorable del sistema de transporte, 98 la falta de productos como dulces, té, huevos, entre otros $99-$ atribuye tales dificultades a los años de guerra y bloqueo, con sus secuelas inmensamente destructivas en términos humanos y materiales, y a las acciones contrarrevolucionarias sistemáticas de la vieja clase dominante, pero también de las potencias occidentales y de los sectores reformistas, cuya prédica actuaría debilitando el poder soviético. A pesar de los problemas económicos en tiempos del comunismo

\footnotetext{
94. Ibíd., p. 15.

95. Ibíd., p. 16.

96. Ibíd., p. 14.

97. Ibíd., p. 15 .

98. Ibíd., p. 14.

99. Ibíd., p. 16.
} 
de guerra, el autor señala que las tareas de reconstrucción está dando sus frutos. ${ }^{100}$ Pero más importante es que todas esas instituciones e iniciativas que se despliegan en la nueva sociedad en Rusia "en tiempos difíciles”, las cuales "están en sus comienzos y deben desarrollarse y mejorarse", constituyen "los cimientos ya echados" de la nueva sociedad, y “sobre ellos se edificará el futuro mejor”. ${ }^{101}$

Lamentablemente, estas "impresiones" de Komin-Alexandrovsky que estamos mencionando aparecen de modo intermitente en el texto. El tono impresionista y reflexivo que promete en los tramos iniciales, se pierde bajo el peso de lo que denominamos la gramática del panfleto. Las distintas temáticas $-\mathrm{y}$ el autor menciona muchas, pero no avanza hacia su problematización- son presentadas como cuestiones que, tendencialmente, avanzarían hacia su resolución y armonización si no interfirieran factores externos a las mismas. ${ }^{102}$ De este modo, ganan terreno los clivajes nítidos organizados en torno a un eje principal, revolucióncontrarrevolución, bajo el supuesto de que ambos términos son, en todos los casos, perfectamente transparentes y discernibles.

La modalidad del panfleto político se manifiesta en largos pasajes. Por ejemplo, cuando recrimina las orientaciones de mencheviques y anarquistas repite los lugares comunes de una crítica simplificadora: que los primeros defienden el libre comercio y la democracia representativa; que los segundos no reconocen la necesidad de la dictadura del proletariado, elemento transitorio de defensa del poder obrero. ${ }^{103}$ Del mismo modo, dedica muchas páginas a atacar furiosamente a Makhno y el

\footnotetext{
${ }^{100}$ Ibíd., p. 17.

${ }^{101}$ Ibíd., p. 17.

${ }^{102}$ Un ejemplo elocuente es cómo aborda la cuestión de la relación entre el poder soviético y el campesinado. El autor describe las actitudes campesinas frente a las imposiciones y requisas, pero igualmente presenta un panorama más que alentador, en donde el campesinado convive con un sistema cooperativista en expansión y un modelo de "fincas del soviet" también cada vez más extendido; estos factores, con ciertas fricciones, estarían encontrando medios colaborativos para resolver sus diferencias, como los "sábados del campesinado" - que Komin-Alexandrovsky menciona como análogos a los "sábados comunistas" - en los cuales el activismo bolchevique y los sectores de la industria (técnicos y obreros) llevarían soluciones y tecnología al campo; cfr. Id., pp. 19-21. Recordemos que en la segunda mitad de 1920 ya era insostenible la tensión entre el campesinado y el gobierno bolchevique.

${ }_{103}$ Ibíd., pp. 8-10, donde los argumentos contra mencheviques y anarquistas son puestos en boca de obreros de Georgia. Sobre los anarquistas que se habrían percatado de las necesidades de la dictadura del proletariado, pp. 25-27. También, sobre cómo la ingenuidad anarquista y socialista revolucionaria contribuye a la contrarrevolución, pp. 28-29. Para atender a las complejidades del debate rioplatense sobre estos temas, remito a los capítlos "Tiempo" y "Régimen" en PITTALUGA, Roberto, Soviets en Buenos Aires..., ob. cit.
} 
movimiento makhnovista, acusándolo con el mismo tipo de adjetivaciones que las fuerzas blancas contrarrevolucionarias utilizaban para con los bolcheviques y que él mismo criticara en las primeras páginas del folleto.104 Las invectivas contra mencheviques, socialistas revolucionarios y anarquistas son contrapuestas a un cerrado elogio del Ejército Rojo -de sus formas organizativas centralizadas y verticales, de su disciplina y moral- que, por momentos, alcanza modulaciones épicas, ${ }^{105}$ pero que carece de profundidad política.

De este modo, bajo la lógica panfletaria, el texto pierde riqueza y complejidad, se instala en una posición defensiva - sin crítica - de la perspectiva bolchevique y resuelve toda situación dilemática en términos de identificaciones plenas. Esta estructura del folleto deriva de un propósito que se explicita sobre el final del texto: allí, Komin-Alexandrovsky retoma el tono intimista del inicio, y dejando a un lado el verbo panfletario escribe como si hablara en una mesa de café con sus camaradas de siempre. ${ }^{106}$ Lo curioso es que no se trata de la militancia del novel Partido Comunista, editor del folleto, sino de sus compañeros de FORSA, muchos de ellos anarquistas o anarcosindicalistas. Este específico destinatario hecha luz sobre la particular estructura del texto: Komin-Alexandrovsky pretende una escritura que, demarcando nítidamente las líneas divisorias a favor y en contra de la revolución rusa -gramática del panfleto y el alineamiento identificatorio- se fundamente también en la palabra testimonial, la propia en sus impresiones en el viaje, la ajena en los relatos puestos en boca de obreros, soldados, camaradas en Rusia, varios de ellos anarquistas -el aspecto impresionista y subjetivo del folleto.

Komin-Alexandrovsky regresa a la Argentina en 1921 como representante de la Internacional Comunista; sus relaciones con la dirección del PCA son tensas y,

104 Sobre Makhno y los makhnovistas, ALEXANDROVSKY, ob. cit., pp. 29, 33, 35-36, 38. Resulta sintomático de la debilidad del modo panfletario, que cuando expone cuáles son los requisitos que demandan los makhnovistas para aliarse con el Ejército Rojo, a los que califica de "viveza", lo que lista son peticiones no sólo perfectamente razonables sino consistentemente políticas y democráticas. Pues, dice Komin-Alexandrovsky, los makhnovistas "aceptarían el comando superior del estado mayor del ejército rojo, si se los dejaba bajo el mando inmediato del «tata Makno» y se les permitía la libre expresión de «sus ideas» con derecho a usar de las imprentas y del papel en condiciones iguales a los demás, en la ciudades evacuadas por los blancos y ocupadas por el ejército rojo”, p. 35.

105 Por ejemplo, en el relato del sacrificio que decide realizar la Compañía 146 de la 3ova. División de los tiradores siberianos en la toma de las fortificaciones de Crimea; cfr. id., pp. 37-38. Como delegado al Congreso de la IC, Komin-Alexandrovsky fue destinado, junto a otros delegados, a trasladarse al frente de guerra contra Wrangel.

106 "Al terminar mis correspondencias he de deciros algo, compañeros...”, id., p. 41. El tono continúa hasta el final del escrito. 
aparentemente, apostaba a sumar a sectores del anarquismo y del anarcosindicalismo. ${ }^{107} \mathrm{Al}$ año siguiente regresó a la Rusia Soviética para trabajar como experto de la Comisión Sudamericana y como mecánico, ayudante de ingeniero, jefe industrial, administrador y director de distintas empresas estatales soviéticas. Falleció en 1968.

Los textos que hemos analizado aquí, de modo preliminar, constituyen un material documental producido por tres exiliados pero cuya situación de producción es muy distinta. Yaroshevsky escribe en Buenos Aires entre 1917 y 1919, para luego partir de vuelta hacia a la Rusia soviética y sus escritos se publican en medios muy diversos, desde los periódicos socialistas, anarquistas y comunistas a diarios de la prensa masiva; de Yaroshevsky podría decirse que escribe con las pocas noticias confiables que llegan al Río de la Plata. Alexandrovsky viaja a Rusia en 1920 y retorna brevemente a la Argentina como representante de la IC durante 1921 y 1922; de su principal escrito, Impresiones de un viaje a la Rusia sovietista, puede decirse que es un texto que surge en el cruce, para nada armonioso, del regreso a sus dos tierras natales (Rusia y también la revolución) con el mandato y la misión militante de la IC. Por su parte, los textos de Gorelik que se publican en la región rioplatense fueron escritos entre 1921 y 1928, y se trata de las elaboraciones de quien ha tenido una experiencia en la revolución pero escribe ya desde el exilio.

Tres situaciones de producción de los textos: una escritura casi a ciegas desde la doble distancia espacial y exiliar; una escritura impactada por el retorno pero también obturada por la luminosidad del sueño realizado; una escritura dolida y dolorosa de un exilio también nuevo, y que conjetura sobre el fracaso de aquella gesta. De ese modo, variables distancias - políticas, materiales, simbólicas, afectivas - se expresan y a la vez trabajan en estas fuentes documentales. Ver la revolución a través de ellas, trabajarlas en su interacción, en sus choques interpretativos, sirve para indagar en aspectos generalmente eludidos por las

$107 \mathrm{Al}$ respecto se pueden consultar JEIFETS, Víctor, "La derrota de los «Lenins argentinos»: La Internacional Comunista, el Partido Comunista y el movimiento obrero de Argentina, 1919-1922", en Pacarina del Sur. Revista de pensamiento crítico latinoamericano, $\mathrm{n}^{0}$ 6, México, enero-marzo. Disp. en: www.pacarinadelsur.com; JEIFETS, Víctor y JEIFETS, Lazar, "La Internacional Comunista y la izquierda argentina: primeros encuentros y desencuentros", en ARCHIVOS de historia del movimiento obrero y la izquierda, año III, $\mathrm{n}^{0}$ 5, septiembre 2014, pp. 71-92. 
interpretaciones que cuentan con los mayores consensos historiográficos.

Bertolt Brecht sostenía que la posición del exilio conllevaba una energía o atributo que dotaba a la mirada de capacidades críticas especiales. El exiliado se encuentra en una posición de compromiso completo y a la vez de apartamiento, cercano pero separado, lo cual posibilita, según el dramaturgo alemán, una acuidad crítica de la mirada capaz de despojar a la realidad de aquello que tiene de evidente y que está producido como sentido antes de su interpretación. Aquí se ha intentado interrogar estos documentos para exponer, a través de ese complejo distanciamientocercanía, y del fragor que generan las interacciones entre significaciones bien disímiles, elementos de la propia revolución que enriquecen su interpretación y dan cuenta de la diversidad de apuestas revolucionarias convivientes en esos años de la primera posguerra.

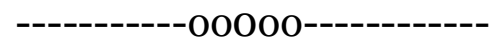

\section{Fuentes y Bibliografía}

\section{Fuentes}

"Pidiendo el reconocimiento de Rusia" (1925), en Revista de Oriente, $\mathrm{n}^{0}{ }_{2}$, julio, $\mathrm{p}$. 28, (artículo sin firma).

ALEXANDROVSKY, Impresiones de un Viaje a la Rusia Sovietista, Buenos Aires, La Internacional, s/f. [1921].

GORELIK, Anatol, “A. M. Atabekian”, La Antorcha, nº 128, Buenos Aires, 18 de abril de 1924, pp. 2-3.

GORELIK, Anatol, "Anarquismo y «anarquismo obrero»", en La Antorcha, no ${ }^{135}$, Buenos Aires, 13 de junio de 1924, pp. 1-2.

GORELIK, Anatol, “Aron Baron”, La Antorcha, no 129, Buenos Aires, 25 de abril de 1924, pp. 2-3.

GORELIK, Anatol, "El anarquismo y la ética (segunda parte)", en La Antorcha, no 125, Buenos Aires, 28 de marzo de 1924, p. 3.

GORELIK, Anatol, “Fanny Baron”, La Antorcha, n 131, Buenos Aires, 16 de mayo de 1924, p. 2.

GORELIK, Anatol, "La educación en la Rusia soviética (poder comunista y educación)", en MINTZ, Frank, (comp.), Anatol Gorelik. El anarquismo y la revolución rusa, Buenos Aires/La Plata, Libros de Anarres/Terramar, 2007, pp. 173-180.

GORELIK, Anatol, "Las causas del fracaso de la revolución rusa", en Pampa Libre. Periódico quincenal anarquista, $\mathrm{n}^{\circ}$ 94-117, Santa Rosa, La Pampa, 15 de septiembre de 1926 al 19 de febrero de 1928. 
GORELIK, Anatol, “Lewa Kogan”, La Antorcha, no 130, Buenos Aires, 2 de mayo de 1924, pp. 2-3.

GORELIK, Anatol, "Voladia Poteckin", La Antorcha, n 132, Buenos Aires, 23 de mayo de 1924, pp. 2-3.

GORELIK, Anatol, La Revolución Social, Buenos Aires, Ediciones del Ateneo Anarquista, 1923, p. 18.

MINTZ, Frank (comp.), Anatol Gorelik. El anarquismo y la revolución rusa, Buenos Aires/La Plata, Libros de Anarres/Terramar, 2007.

PESTAÑA, Ángel, Memoria que al Comité de la Confederación Nacional del Trabajo presenta de su gestión en el II Congreso de la III Internacional, Madrid, Nueva Senda, 1921.

YAROSHEVSKY , Mijail, "Estudio sobre la revolución rusa”, Documentos del progreso, $\mathrm{n}^{\circ}$ 6, Buenos Aires, 15 de octubre de 1919, pp. 8-14.

YAROSHEVSKY, Mijail, "El espíritu de la revolución rusa”. La Vanguardia, Buenos Aires, 10 de junio de 1917, p. 2.

YAROSHEVSKY, Mijail, "Escenas de la revolución rusa en provincia (con motivo del primer aniversario)”, Nosotros, año 12, no 108, Buenos Aires, abril de 1918, pp. 463-472.

YAROSHEVSKY, Mijail, "La revolución en Rusia”, Nosotros, año XI, nº 95, Buenos Aires, marzo 1917, pp. 289-94.

YAROSHEVSKY, Mijail, "La tragedia rusa. Figuras del gobierno maximalista", en La Protesta, Buenos Aires, 24 de noviembre de 1917, p. 2.

\section{Bibliografía}

DOESWIJK, Andreas, Los anarco-bolcheviques rioplatenses, Buenos Aires, CeDInCI Editores, 2014.

FIGES, Orlando; KOLONITSKII, Boris, Interpretar la Revolución Rusa. El lenguaje y los símbolos de 1917, Valencia, Biblioteca Nueva/Universitat de València, 2001.

JEIFETS, Lazar; JEIFETS, Víctor, América Latina en la Internacional Comunista, 1919-1943. Diccionario Biográfico, Santiago de Chile, Ariadna Ediciones, 2015.

JEIFETS, Lazar S. y ANDREEV, Anton S., "A. Gorelik: Argentinean touches of Russian Revolution Portrait” (“А. Горелик: аргентинские штрихи к портрету русской революции”), Bylye Gody, Sochi State University, 2015, Vol. 36, Is. 2, pp. 394-402.

JEIFETS, Víctor y JEIFETS, Lazar, "La Internacional Comunista y la izquierda argentina: primeros encuentros y desencuentros", en ARCHIVOS de historia del movimiento obrero y la izquierda, año III, $\mathrm{n}^{0}$ 5, septiembre 2014, pp. 71-92.

JEIFETS, Víctor, "La derrota de los «Lenins argentinos»: La Internacional Comunista, el Partido Comunista y el movimiento obrero de Argentina, 19191922”, en Pacarina del Sur. Revista de pensamiento crítico latinoamericano, no 6, México, enero-marzo 2011. Disp. en: www.pacarinadelsur.com 
MINTZ, Frank, “Anatol Gorelik”, en TARCUS, Horacio, Diccionario biográfico de las izquierdas argentinas. De los anarquistas a la "nueva izquierda" (1870-1976), Buenos Aires, Emecé, 2007, pp. 284-86.

PITTALUGA, Roberto "De profetas a demonios: recepciones anarquistas de la revolución rusa. Argentina, 1917-1924”, en Sociohistórica. Cuadernos del CISH, $\mathrm{n}^{\mathrm{0}}$ 11/12, FaCHE-UNLP, primer y segundo semestre de 2002, pp. 69-98.

PITTALUGA, Roberto, "Lecturas anarquistas de la revolución rusa", en Prismas. Revista de Historia Intelectual, Universidad Nacional de Quilmes, $\mathrm{n}^{0}$ 6, 2002, pp. 179-188.

PITTALUGA, Roberto, Soviets en Buenos Aires. La izquierda de la Argentina ante la revolución en Rusia, Buenos Aires, Prometeo Libros, 2015.

SAÍTTA, Sylvia, Hacia la revolución. Viajeros argentinos de izquierda, Buenos Aires, FCE, 2007. 